\title{
El Protocolo en la docencia universitaria: la materia de Relaciones Públicas y Protocolo en el marco de la adaptación al Espacio Europeo de Educación Superior
}

\author{
Juan Manuel CoRBACHO VALENCIA \\ Universidad de Vigo \\ jmcorbacho@uvigo.es
}

Recibido: 05/11/2012

Aceptado: 23/01/2013

\begin{abstract}
Resumen
Ya son casi tres décadas de reivindicación por parte de los profesionales y académicos del protocolo que han culminado en la creación de un grado en Protocolo y Organización de Eventos en la Universidad Camilo José Cela como hito histórico reciente. El presente artículo se enmarca en este contexto y analiza la trayectoria de la disciplina del protocolo en la Facultad de Ciencias Sociales y de la Comunicación de la Universidad de Vigo, así como su adaptación al Espacio Europeo de Educación Superior (EEES) en lo que a metodología docente se refiere.

Palabras clave: protocolo, organización de eventos, metodología docente

\section{Protocol in Academic Studies: the Subject "Public Relations the European Higher Education Area} and Protocol" in the Context of its Adaptation to
\end{abstract}

\begin{abstract}
It's now for almost three decades that professionals and academics in the field of protocol demand this disciplines to be recognized at both levels. With the recent creation of the official degree in Protocol and Event Organization at the Universidad Camilo José Cela a huge step has been done in this direction. The present paper aims at analyzing the trajectory of the discipline in the School of Communication and Social Sciences of the University of Vigo and describing its adaptation to the European Higher Education Area (EHEA) as for teaching methods.
\end{abstract}

Keywords: protocol, event organization, teaching method

\section{Referencia normalizada}

CORBACHO VALENCIA, Juan Manuel (2013): "El Protocolo en la docencia universitaria: la materia de Relaciones Públicas y Protocolo en el marco de la adaptación al Espacio Europeo de Educación Superior". Estudios sobre el Mensaje Periodístico. Vol. 19, Núm. especial marzo, págs.: 121-128. Madrid, Servicio de Publicaciones de la Universidad Complutense.

Sumario: 1. Introducción. 2. La cuestión terminológica. 3. El Protocolo en los planes de estudio en Publicidad y Relaciones Públicas. 4. La materia "Relaciones Públicas y Protocolo" entre la licenciatura y el grado. 5. Conclusiones. 6. Referencias bibliográficas.

\section{Introducción}

El reconocimiento de los estudios de protocolo sigue siendo una de las principales reivindicaciones que se han hecho notar en múltiples encuentros, seminarios, foros y publicaciones del sector. Cabe subrayar que ya son casi tres décadas en las que esta disciplina viene reclamando su lugar y reconocimiento tanto en el ámbito académico como en el profesional. Fue Felio Vilarrubias que dio el primer paso con su iniciativa 
pionera de un curso de Experto Universitario a finales de la década de los ochenta en la Universidad de Oviedo. Ya en 1993, se crea en Oviedo la Escuela Internacional de Protocolo. En el curso 1997/1998 surge el primer curso de estudios propios de Protocolo y Relaciones Institucionales (Universidad Miguel Hernández de Elche y Universidad de Granada). En el 2000 se plantea por primera vez en el Congreso de Valencia la oficialización de los estudios y cuatro años después, en el Congreso de Madrid, se comenzó ya a hablar de los profesionales como "gestores de eventos" (García, 2010: 18). En el 2007 la Universidad Camilo José Cela inicia los estudios en Producción y Realización de eventos para finalmente obtener en el 2010 la acreditación de la Agencia Nacional de Evaluación de la Calidad y Acreditación (ANECA) para el Grado en Protocolo y Relaciones Institucionales, hecho ampliamente celebrado por el sector.

Tras esta primera aproximación, podemos observar que la disciplina del protocolo comenzó abriéndose camino con másteres, cursos de especialista o expertos y títulos propios para posteriormente ir buscando su hueco en los planes de estudio de las diplomaturas y licenciaturas del ámbito de las ciencias de la comunicación, en particular de la de Publicidad y Relaciones Públicas y en menor medida la de Periodismo. Sierra Sánchez y Sotelo González (2008: 10 y ss.) señalan en su estudio sobre el estado actual del protocolo a nivel jurídico y profesional, se imparten materias de protocolo en 11 de las 34 titulaciones (un 32,4\%) con una oferta de 11 postgrados relacionados, siendo una de ellas la Facultad de Ciencias Sociales y de la Comunicación de la Universidad de Vigo, objeto de este trabajo.

Igualmente y fuera de este ámbito, los medios de comunicación se hacen cada vez más eco de cuestiones protocolarias en varios ámbitos, eso sí, con enfoques más centrado en lo anecdótico o lo erróneo en su aplicación. También queremos señalar que aún existiendo textos normativos como el Real Decreto 2099/83 del 4 de agosto y sucesivos textos complementarios, así como normas adoptadas por costumbre, detrás de la actividad protocolaria hay personas que, según el caso, la pueden facilitar o complicar. Una de las conclusiones de las Jornadas Internacionales de Comunicación Institucional e Imagen Pública - XII Curso Complementario de Comunicación y Protocolo, celebrado el 9 y 10 de mayo de 2012 en la Facultad de Ciencias Sociales y de la Comunicación de la Universidad de Vigo, señala la falta de sensibilidad e incluso conocimientos por parte de las autoridades públicas sobre las exigencias de la propia responsabilidad que asumen con respecto a la sociedad lo que puede llevar a situaciones no deseadas para los profesionales y que desembocan en graves errores que afectan a la representación simbólica de las instituciones. No sólo supone un reto por la materia en sí, sino por la interacción humana, siendo el protocolo la suma de los conocimientos, la experiencia y la capacidad de improvisación. Esas mismas conclusiones también recogen que las buenas maneras, la cortesía y la urbanidad no son conceptos obsoletos, sino elementos necesarios a la convivencia social. La educación es un lenguaje universal valorado y admirado por todas las personas que lo aplican en sus relaciones sociales y profesionales con la intención de que su comunicación interpersonal sea eficaz y positiva. En resumen, el protocolo no sólo es una herramienta válida en el ámbito institucional o privado, sino que también transciende al social y 
privado, hecho que se ve corroborado en la "Declaración Institucional de la Asamblea General de la AEP". Los profesionales defienden que el Protocolo debe ser considerado como una inversión rentable y duradera ligada a la correcta difusión de la imagen de las entidades y la divulgación de sus actividades, resultados y presentaciones. La Asamblea General de la AEP no sólo quiere dignificar la profesión, sino también manifestar su convicción en la necesidad de potenciar y acrecentar el protocolo, tanto en lo oficial como en lo empresarial, apostando decididamente por la defensa de los intereses de profesionales e instituciones que desarrollan mucha de su actividad desde parámetros protocolarios.

Por todo lo expuesto entendemos que la disciplina del protocolo no sólo ha pasado del ámbito oficial o público al privado, sino que empieza a recibir un reconocimiento implícito en nuestra opinión merecido. El objeto del presente estudio se refiere, pues, a la trayectoria de la materia "Relaciones Públicas y Protocolo" en los tres planes de estudio de Publicidad y Relaciones Públicas que se han aprobado en la Universidad de Vigo y que acoge la Facultad de Ciencias Sociales y de la Comunicación desde 1994. A ello se suma una propuesta y reflexión metodológica de una materia que tiene que aunar conocimiento teórico práctico, pero también experiencia y capacidad de improvisación. Para ello se han utilizado como fuentes los principales autores de la materia reseñados en la bibliografía, la Revista Protocolo como publicación de referencia del ámbito, las publicaciones en el Boletin Oficial del Estado (B.O.E.) de los planes de estudio, así como la citada AEP y la Escuela Internacional de Protocolo (EIP) como referentes del ámbito profesional y académico del sector.

A continuación profundizaremos en la materia "Relaciones Públicas y Protocolo" y su contextualización en los tres planes de estudio de Publicidad y Relaciones Públicas que se han puesto en marcha en la Universidad de Vigo desde la creación de la entonces Facultad de Ciencias Sociales en septiembre de 1994, pero no sin antes aclarar la cuestión terminológica que viene rodeando al protocolo y a día de hoy sigue sin aclararse completamente.

\section{La cuestión terminológica}

En la actualidad está resurgiendo el debate en torno al valor económico de la lengua. Si bien el ámbito que nos ocupa no está exactamente relacionado con esa discusión, no es menos cierto que profesionales y estudiosos del protocolo no acaban de ponerse de acuerdo en torno a la denominación exacta de la disciplina y de aquellos que la desempeñan o la llevan a la práctica.

A priori el término "protocolo" parece estar cargado de ciertos prejuicios que pretenden limitarlo a una serie normas de encorsetamiento de conducta e indumentaria. Si retomamos las célebres palabras de Shakespeare que proclamaba que "Más batallas se han ganado con la sonrisa que con la espada" y las unimos a las de Talleyrand, diplomático francés en la época napoleónica, quien pronto advirtió que sólo los tontos se burlaban del protocolo porque simplifica la vida, tendremos el punto de partida del planteamiento de este trabajo. No es objeto de este estudio reproducir las definiciones del término como las que pueden ofrecer grandes expertos como de Urbina, López-Nieto y Mallo, Marín Calahorro, Otero Alvarado o Vilarrubias, entre otros, 
pero sí queremos dejar constancia de que en el contexto actual de una comunicación marcada por los intangibles, el protocolo ocupa un lugar destacado en el saber ser, saber estar y saber hacer tanto de las instituciones y empresas como de aquellos que las representan o por sí mismos se han convertido en una marca con imagen propia. Resumiríamos dichas definición en que el protocolo se puede considerar un conjunto de normas, costumbres y técnicas necesarias para la realización de los actos, ya sean públicos o privados, y la ordenación de los asistentes y accesorios.

Así, se habla de protocolo, ceremonial, relaciones externas, relaciones institucionales, relaciones públicas, protocolistas, ceremonialistas u organizadores de eventos, entre otros. Eso sí, parece existir cierto consenso, también por las prácticas de otros países, que el protocolo se adecúa más al ámbito estrictamente oficial y relacionado con casas reales y las esferas diplomáticas. En relación con esto, Victor García de la Concha, Director del Instituto Cervantes y Director Honorífico de la Real Academia Española de la Lengua (RAE), declaró recientemente en una entrevista concedida a la Revista de Protocolo que "La RAE revisará el término 'protocolo' para adaptarlo al mundo de los eventos", en concreto para la vigesimotercera edición del diccionario prevista para el 2014 porque el protocolo del siglo XXI abarca mucho más de lo que recoge el diccionario (Palenzuela, 2012:70). Una vez aclarada la cuestión terminológica, ahondamos en su protagonismo en los planes de estudio de Publicidad y Relaciones Públicas.

\section{EI Protocolo en los planes de estudio en Publicidad y Relaciones Públicas}

En el curso 2012/2013 se está implementando el cuarto curso del grado en Publicidad y Relaciones Públicas con lo que se imparte por primera vez en la mencionada facultad como materia con créditos ECTS. Se trata del tercer plan de estudios desde la puesta en marcha de los estudios en el curso 1994/1995. Tanto es así, que la materia "Relaciones Públicas y Protocolo" no aparece en el primer plan de estudios (BOE, 23 de noviembre de 1994), siendo tangencialmente abarcada en la materia de "Teoría de las Relaciones Públicas" del segundo curso. Ya en el segundo plan de estudios figura como materia optativa de cuarto curso de la licenciatura dentro del itinerario de Relaciones Públicas y Comunicación Institucional (BOE, 22 de agosto de 2008). La carga lectiva es de seis créditos teóricos, hecho que también matizaremos en el apartado de adaptación al EEES. Bien es cierto que, a diferencia del primer plan de estudios, se recogen contenidos de protocolo en las materias de "Introducción a la Teoría y Práctica de las Relaciones Públicas" de segundo curso, así como en "Programación y Técnicas de las Relaciones Públicas" de tercer curso. Finalmente, en el Grado en Publicidad y Relaciones Públicas (BOE, 1 de noviembre de 2010) también figura dicha asignatura como optativa, en este caso del primer semestre del cuarto curso con una carga lectiva de 6 créditos ECTS, es decir, 150 horas para el alumno, divididas en 50 horas presenciales y 100 horas de trabajo autónomo, ya sea a nivel individual o grupal y que desglosaremos en lo que sigue. Siguiendo la proyección descrita, también en el grado se ha aumentado la presencia directa e indirecta del protocolo en otras materias como "Teoría y Práctica de las Relaciones Públicas" de primer curso, "Técnicas de Relaciones Públicas" y "Planificación Estratégica de las Relaciones Públi- 
cas", ambas de tercer curso, con lo que si bien sigue ofertándose tan solo una materia de protocolo, sí se han incorporado contenidos relacionados en otras materias y se aumenta su presencia.

\section{La materia "Relaciones Públicas y Protocolo" entre la licenciatura y el grado}

Cabe destacar aquí nuevamente el carácter íntegramente teórico de la materia planteado en el segundo plan de estudios, pero que, como veremos hemos intentado adaptar a los estándares del Plan Bolonia desde un principio. Y es que una materia como la de "Relaciones Públicas y Protocolo" sin parte práctica carece de sentido ya que cada vez más se buscan profesionales preparados en este ámbito. Comenzando, pues, por la parte teórica, el programa está divido en cinco grandes bloques que versan sobre la historia y definición, el protocolo oficial, el protocolo social, la organización de actos, el protocolo en la empresa y finalmente el protocolo en las negociaciones a nivel internacional. Dicha división responde a criterios de lógica histórica, comenzando por los orígenes y la definición. El alumno suele tener una idea acerca de los contenidos del protocolo, pero desconoce aquellas partes que lo diferencian de las relaciones públicas. De hecho, y a pesar de la denominación de la materia, no se producen duplicidades de contenidos ya que no se abordan aspectos específicos de las relaciones públicas, si bien resulta inevitable hacer referencia a ellas, especialmente en el tema de la organización protocolaria de eventos.

Una vez aclarado el origen y el concepto, seguimos la lógica histórica y pasamos a abordar el protocolo oficial ya que es donde se sientan las bases para todas las demás aplicaciones. No puede faltar aquí la referencia al Real Decreto 20099/83 del 4 de agosto, los poderes del Estado, así como el Tribunal Constitucional y la Casa Real. Le sigue el tema relativo al protocolo social con apartados que van desde técnicas de colocación de mesas y normas de etiqueta y urbanidad. Destaca especialmente la atención prestada aquí a la comunicación verbal y escrita en todas sus manifestaciones.

En cuatro lugar se aborda la organización protocolaria de los actos desde un punto de vista logístico y no tanto de relaciones públicas, en esencia, los pasos que hay que dar para que dicho evento funcione.

El quinto tema versa sobre el protocolo en la empresa y como en mayor o menor medida se ha aplicado lo visto hasta aquí en el ámbito privado como elemento diferenciador de la comunicación.

Cierra el temario teórico el apartado sobre aspectos a tener en cuenta para posibles negociaciones a nivel internacional. Se eligen cada año los diez países con mayor índice de exportación desde España. La internacionalización de las empresas, incluidas las PYMES, está ya al orden del día y es una práctica habitual acompañar a los responsables en sus viajes. En este sentido, hay que garantizar que dominen una serie de aspectos para actuar con corrección según lo exige la cultura, costumbre o etiqueta imperante en cada país.

En cuanto al aspecto práctico de la presente asignatura, ausente como vimos en términos del segundo plan de estudios, pero sí a tener en cuenta en el nuevo grado con seminarios y prácticas, hemos intentado elaborar un esquema siguiendo las principales competencias definidas y adaptadas para la materia en cuestión según lo estable- 
cido en la memoria del grado ${ }^{1}$. A partir de aquí nos hemos planteado un esquema de aprendizaje colaborativo con escenarios, simulaciones (Baamonde, 2010: 268) y trabajos diversos que pretenden acercar al estudiante al mundo del protocolo en la medida de las posibilidades que ofrecen las propias instalaciones del centro y el trabajo autónomo del alumno.

Los seminarios y prácticas coincidirán con las unidades temáticas señaladas. Como primera sesión práctica está prevista una toma de contacto con la disciplina del protocolo a través de un cuestionario con aspectos básicos para poder evaluar el nivel inicial y contrastarlo con la prueba final. La siguiente sesión consistirá en un análisis pormenorizado del Real Decreto 2099/83 del 4 de agosto para detectar sus puntos potenciales y sus debilidades como texto de referencia en cuanto a ordenación de precedencias en el ámbito oficial se refiere bajo la cada vez mayor necesidad de actualización del mismo. Le sigue el primero de los escenarios dentro del protocolo oficial con un caso hipotético en el que los condicionantes serán la asistencia de autoridades oficiales y no oficiales, el lugar de la celebración, la fecha y las circunstancias que marcan el acto desde un punto de vista político y social. Se trata de que el alumno sepa discernir la figura del anfitrión, la ordenación de los asistentes y el orden de los discursos. No obstante, el alumno deberá ser consciente de que la propia ordenación de los asistentes no es el principal quebradero de cabeza, sino que tendrá que prestar atención a todos los detalles como las secuencias y el ceremonial del acto. Otro seminario estará dedicado a la visita de un profesional del sector, en este caso de la Diputación de Pontevedra. Preferimos invitar a antiguos alumnos de la propia facultad porque no sólo aportan información específica acerca de su trabajo, sino que también pueden compartir su experiencia en la búsqueda de empleo, información de especial interés para los alumnos que están cursando el último curso de la carrera, por no hablar del elemento motivador inherente. En la parte de protocolo social, los alumnos tendrán mayor carga de trabajo autónomo al tener que organizar la celebración de la boda con el encargo de una pareja que desea un festejo distinto a lo habitual. Dicha actividad será evaluada y supervisada en otro seminario por dos alumnas que han cre-

\footnotetext{
A saber: Conocer los fundamentos y orígenes de la disciplina del protocolo tanto desde su vertiente oficial como en su aplicación al ámbito social y privado; comprender las diferencias y puntos entre las Relaciones Públicas y el Protocolo; adquirir las técnicas necesarias para la organización de cualquier tipo de acto y desarrollar los materiales mínimos necesarios para cerrar una adecuada logística en la organización de los actos; interpretar experiencias ajenas en la organización de actos; analizar actos reales mediante el seguimiento presencial y a través de los medios de comunicación; reflexionar acerca de modelos de organización de gabinetes de protocolo en entidades públicas y privadas; diferenciar disposiciones legales en materia de protocolo; diseñar y aplicar técnicas de organización de actos, sus asistentes y demás partes implicadas en su correcto desarrollo; planificar el desarrollo de actos públicos y privados desde su proyección inicial hasta su evaluación; resolver estratégicamente los espacios protocolarios de los actos; manejar correctamente todos los materiales incluidos en la documentación de Protocolo; asumir la filosofía de la entidad y reflejarla en la organización del acto; dirigir e integrarse a equipos de planificación y organización de eventos; interiorizar técnicas de comunicación escrita y oral; dar respuesta a cuestiones no previstas en la planificación de un acto; responsabilizarse de las decisiones organizativas y funcionales adoptadas.
} 
ado su propia empresa de organización de eventos que también ofrecerán su visión del sector y del trabajo en sí. Con ello se inicia los seminarios y prácticas relativas a la organización de eventos en la que los alumnos tendrán que elegir una empresa real de la provincia de Pontevedra y organizar un evento de relieve para su entorno más inmediato. En una práctica individual los alumnos tendrán que realizar una serie de encargos escritos para mejorar su calidad de redacción, a saber, un telegrama de condolencia, un fax, una felicitación, un correo electrónico, un tweet y una invitación a un congreso. Los textos serán cronometrados y para cada uno de ellos daremos los datos básicos. Antes de pasar al último bloque temático acerca del protocolo internacional, los alumnos deberán presentar el trabajo de curso que versará sobre algún aspecto específico de protocolo que no se haya tratado en el programa. La presentación será tanto oral como escrita y en público, siendo dichos trabajos parte de la teoría y, por tanto, susceptibles de entrar en el examen. Al igual que el profesor a final del cuatrimestre es evaluado por el alumnado, serán en este caso los propios alumnos que valoren a sus compañeros en base a la presentación en clase que no durará más de quince minutos. En la parte de protocolo internacional los alumnos se convertirán en asesores para crear un decálogo de normas de conducta para el viaje de negocios. A ello se suma un seminario al que invitaremos a las responsables de la Denominación de Origen Rías Baixas para que expongan sus experiencias en la comercialización de sus vinos en el extranjero, especialmente en el mercado estadounidense y asiático. La evaluación de la materia se completa con un examen teórico tipo test y con preguntas para rellenar huecos con una pregunta de cada uno de los trabajos presentados.

\section{Conclusiones}

El protocolo es consustancial a la sociedad en la que vivimos y no deja de estar vertebrado en el mundo profesional desde un punto de vista comunicativo. Sin duda, ha alcanzado la mayoría de edad como disciplina y buena muestra de ello no sólo es la oferta formativa culminada con un grado en Protocolo y Organización de Eventos, sino también la concienciación en el sector profesional de necesitar profesionales específicos del sector. A ello se suman las múltiples asociaciones del sector y la existencia de un Observatorio profesional, por no hablar del Premio Internacional de Protocolo. Si bien se nos antoja corto el valor otorgado en los planes de estudio analizados, entendemos que la oferta académica sigue en continuo crecimiento no sólo debido a la mayor concienciación de los distintos sectores acerca de su importancia en el contexto económico-social. En este sentido, la materia "Relaciones Públicas y Protocolo" se impartió en la licenciatura con una metodología claramente orientada a los principios expuestos en el Plan Bolonia para facilitar la transición al Grado en Publicidad y Relaciones Públicas. Obviamente existen partes del mundo real que son difícilmente trasladables a la docencia universitaria porque a fin de cuentas la organización de actos choca con los egos y el desconocimiento de las normas protocolarias de alguna de las partes implicadas, así como con imprevistos de última hora. $\mathrm{Al}$ margen de las advertencias oportunas también intentamos que los profesionales que colaboran en los seminarios ofrezcan una visión distinta a la habitual, una visión propia del día a día, incluyendo anécdotas, pero también experiencias a priori negati- 
vas. Resulta difícil, por no decir imposible, transmitir experiencia y capacidad de improvisación en un aula, de ahí la insistencia en los estudios de caso y las mencionadas visitas. No en vano, el estudiante está a punto de enfrentarse a otro mundo distinto al académico para trabajar en un ámbito formación no concluye con la obtención del título.

En definitiva, el grado y el fortalecimiento de estudios en protocolo supondrá un cambio de la forma de entender la organización de eventos en España. Es un respaldo académico que de alguna forma dignifica la profesión y dará cabida a la creación de un colegio de profesionales.

\section{Referencias bibliográficas}

ASOCIACIÓN ESPAÑOLA DE PROTOCOLO (2012) "Declaración Institucional de la Asamblea General de la AEP", en: http://www.revistaprotocolo.es/images/stories/PDF/DECLARACIONAEP.pdf [fecha de consulta: 20 de septiembre de 2012]

DE URBINA, José Antonio (2001): El gran libro del protocolo. Madrid, Temas de Hoy.

GARCÍA, Ismael (2010): “Un largo camino”, en Revista Protocolo, nº 56, pp. 18-22.

LÓPEZ NIETO Y MALLO, Francisco (2003): Manual de protocolo. Barcelona, Ariel.

MARÍN CALAHORRO, Francisco (2004): El protocolo en los actos de empresa: la gestión de eventos corporativos. Madrid, Fragua.

OTERO ALVARADO, María Teresa (2001): Relaciones Públicas y Protocolo: cinco años de reflexiones. Sevilla, Laurea.

PALENZUELA, Ana (2012): "La RAE revisará el término 'protocolo' para adaptarlo al mundo de los eventos", en Revista Protocolo, no 63, pp. 70-76.

SIERRA SÁNCHEZ, Javier y SOTELO GONZÁLEZ, Joaquín (2008): "El estado actual del protocolo a nivel jurídico y profesional", en Icono 14, 11, pp. 1-34.

SIERRA SÁNCHEZ, Javier y SOTELO GONZÁLEZ, Joaquín (2010): Métodos de innovación docente aplicados a los estudios de Ciencias de la Comunicación. Madrid, Fragua.

VILLARUBIAS, Felio (2000): Tratado de protocolo de estado e internacional. Oviedo, Nobel.

\section{Juan Manuel CORBACHO VALENCIA}

Universidad de Vigo

Decano de la Facultad de Ciencias Sociales y de la Comunicación

Profesor del Departamento de Comunicación Audiovisual e Publicidade

jmcorbacho@uvigo.es 